\title{
Laparoscopic retrieval of displaced Copper T: Two case reports
}

Bajracharya $A^{1}$, Saha $R^{2}$

${ }^{1}$ Anu Bajracharya, Lecturer; ${ }^{2}$ Rachana Saha, Associate Professor and Head; Department of Obstetrics and Gynaecology, Kathmandu Medical College Teaching Hospital, Kathmandu, Nepal.

\section{Abstract}

Intrauterine contraceptive device (IUCD) is a widely accepted contraceptive method because of its safety, economic quality, efficiency and reversibility. However, it may cause serious complications like bleeding, uterine perforation and migration to abdominopelvic cavity with perforation or adhesion to adjacent organs or omentum. We report two cases of uterine perforation with copper T insertion that were displaced in the pelvic cavity. In both the cases, IUCD was located by using plain X-rays of abdomen, ultrasonography, and hysteroscopy and finally laparoscopy was performed to identify the location and then remove the IUCD.

Key words: Intrauterine contraceptive device, Hysteroscopy, Laparoscopy, Uterine perforation

\section{INTRODUCTION}

$\mathrm{T}$ he intrauterine contraceptive devices (IUCD) are popular, safe and convenient methods of long term reversible birth control. Over the years various types of intrauterine devices were used and currently most commonly used intrauterine devices include T Cu380A and levonorgestrel (Mirena). These are highly effective devices with failure rate of less than one per 1000 women per year ${ }^{1}$. The IUCD string is used to monitor the presence or absence of the device and for the removal of the device. The primary diagnosis of lost string may be the broken string, loss completely, with drawn into the uterus cavity, expulsion outside, uterine perforation and translocation of the device in to the abdominal cavity ${ }^{2}$. The clinical presentation following perforation and migration is highly variable ranging from asymptomatic to acute abdomen due to infection, adhesion or bowel obstruction $^{3}$ or perforation ${ }^{4}$. The accepted method of treatment of displaced IUCD is surgical removal because of its putative risk of adhesion formation or of damage to the intestine or urinary bladder ${ }^{5}$. Its retrieval can be accomplished by hysteroscopic guided uterine exploration, diagnostic curettage, laparoscopy or laparotomy depending upon its location and availability

\section{Address for correspondence}

Dr. Anu Bajracharya

Lecturer

Department of Obstetrics and Gynaecology, Kathmandu Medical

College Teaching Hospital, Kathmandu, Nepal.

E-mail: dr.anubajracharya42@gmail.com of equipments, expertise of the health care provider and facility.

\section{CASE REPORTS}

\section{CASE 1}

A 28 year old para one lady presented with the complaints of lower abdominal pain, continuous in nature and not relieved by analgesics. She had inserted copper $\mathrm{T}$ at a health post five months back at six weeks post partum, following lower segment caesarean section delivery. Her general condition and systemic examinations were normal. Per vaginal speculum examination showed cervical erosion but the loop of threads of copper $T$ were absent. The plain X-ray of abdomen and pelvis with antero-posterior (AP) and lateral view showed displaced position of copper $T$ to far right lateral wall of pelvis in an upside down position (Figure 1). The USG examination revealed copper $\mathrm{T}$ in the fallopian tube. The hysteroscopic examination combined with laparoscopy was performed. Hysteroscopic examination showed no copper $T$ inside the uterine cavity. Then laparoscopy was performed and the copper $T$ with its thread was seen attached to the right pelvic wall adherent with a portion of omentum (Figure 2). After adhesiolysis of the attached portion of omentum, the IUCD was then grasped with the grasper and removed from the secondary port site to be mentioned. Postoperative recovery was satisfactory and the patient was discharged home the next day. 


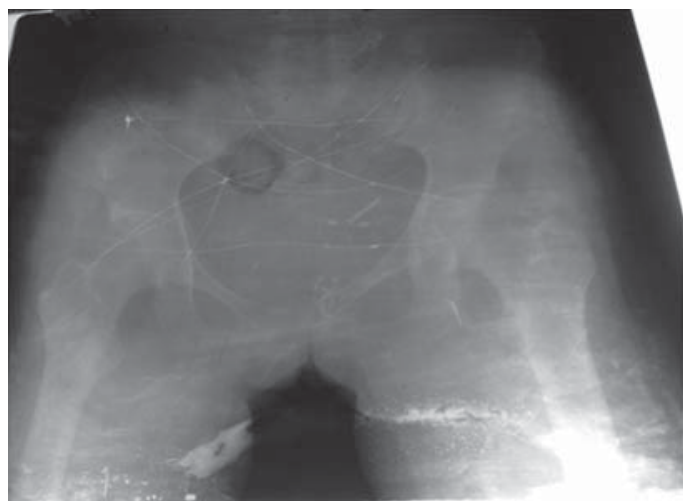

Figure 1: X-ray showing extrauterine displacement of IUCD
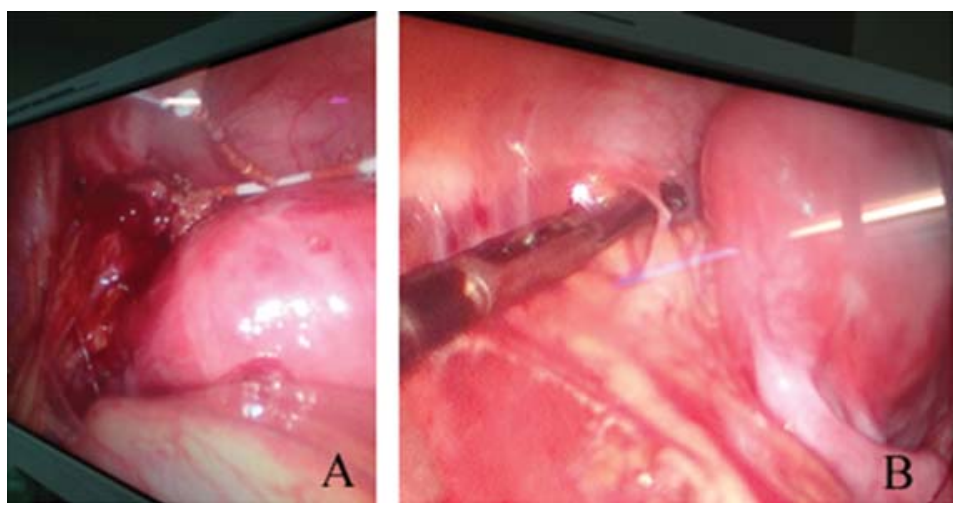

Figure 2 ( $A$ and B): Laparoscopic view of IUCD (Copper-T) embedded in lateral pelvic wall.

\section{CASE 2}

A 30 year old para two lady presented with the complaints of lower abdominal pain and leucorrhoea. She had copper $\mathrm{T}$ inserted following a medical termination of pregnancy (MTP) done two months back. She was having continuous pain at the supra pubic region since the insertion of IUCD so came for consultation. The general examination and systemic examination were normal. Abdominal examination revealed tenderness over the supra pubic region. Per vaginal speculum examination showed cervical erosion with thick discharge and the thread of IUCD could be seen, however, the uterine sound could not feel the stem part of the IUCD inside the cervical canal or uterine cavity. The plain X-ray of abdomen and pelvis AP and lateral view showed displaced copper T near to the symphysis pubis lying in an oblique position. USG examination revealed empty uterine cavity and the IUCD was seen lying partly over the dome of the bladder and partly in the anterior wall of body of uterus. The hysteroscopic examination showed only loops of thread but not the vertical stem and T part of the copper T. The thread was removed with the help of artery forceps under direct vision of hysteroscope. Laparoscopic examination showed copper T without the thread embedded in the anterior pelvic wall just above the dome of the urinary bladder with few thin flimsy adhesions. The IUCD was grasped with the grasper and on giving a sharp pull it was separated from the anterior pelvic wall. The IUCD was thus recovered intact from the secondary port. Postoperative period was uneventful and she was discharged the next day.

\section{DISCUSSION}

Displacement of IUCD may be due to expulsion or perforation. Expulsion, however, seems to be more common ${ }^{6}$. But any missing IUCD should be aggressively sought for. Uterine perforation and translocation is an unusual complication of an IUCD, occurring in 1.3/1000 insertions ${ }^{7}$. Uterine perforation usually occurs during insertion and may be partial, with only a portion of an IUCD piercing the uterine wall or cervix or complete involving adjacent pelvic organs, such as the bladder, appendix or recto-sigmoid colon. Arslan et $\mathrm{al}^{8}$ in a review of the literature identified 47 cases of uterine perforation complicated by intestinal penetration. Risk factors for perforation include clinician's inexerpertise in IUCD placement, decreased mobility or retroverted uterus or insertion in lactating mothers when the uterine wall is thin ${ }^{9}$. In our first patient, perforation occurred during lactational period and in the second patient, after completion of MTP when uterus was soft. In a case control analysis, breast feeding women had more than 10 fold greater risk of uterine perforation at IUCD insertion than non-breast feeding women ${ }^{10}$. In both cases we had successfully diagnosed and removed the IUCD through five $\mathrm{mm}$ port with minimal bleeding. The best step to diagnose and assess the missing IUCD is by sonographic scan which could determine the presence or absence of the IUCD. If IUCD cannot be visualised in the ultrasound then a plain abdominopelvic X-ray is necessary to note the site of an IUCD as the stem of IUCD contains radio opaque substances. Balci et al ${ }^{11}$ had also reported 18 cases of intra-abdominal dislocated IUCDs, which were diagnosed by gynaecological examination, abdominal X-ray and ultrasonogram scan and for all those patients, laparoscopy was performed for removal of IUCD. Laparoscopy, being less invasive, is a safe and successful procedure for removal of displaced IUCD.

\section{CONCLUSION}

Uterine perforation is the most serious complication associated with intrauterine contraceptive device (IUCD). 
Minimally invasive techniques, such as hysteroscopy and laparoscopy, are ideal diagnostic and surgical management of intra-abdominally dislocated IUCD due to uterine perforation. In addition, this case report also highlights the need for trained personnel for its insertion as well as a regular follow-up.

6. Speroff L, Fritz MA, Glass RH, Kase NG. Clinical gynaecology endocrinology \& infertility. 7th ed. William \& Wilkins; 2005.983 p.

7. Andersson K, Ryle-Blomqvist E, Lindell K, Odlind V, Milson. Perforation with intrauterine devices: report from a Swedish Survey. Contraception.1998;57:251-5.

8. Arslan A, Kanat-Pektas M, Yesilyurt H. Colon penetration by a copper intrauterine device: a case report with literature review. Arch Gynecol Obstet. 2009;279:395-7.

9. Dean $G$, Goldberg A. The intrauterine contraceptive device [Internet]. 2004 [cited 2010 Jun 5]. Available from: http://www.update.com

10. Chi I. What have we learned from recent IUD studies: A researcher's perspective. Contraception. 1993;48:90-1.

11. Balci O, Mahoud AS, Capar M, Colakouqlu MC. Diagnosis and management of intraabdominal, mislocated intrauterine devices. Arch Gynecol Obstet. 2010 Jun;281(6):1019-22. 